\title{
CONSTRUÇÃO DE HISTÓRIAS EM QUADRINHOS COMO RECURSO DIDÁTICO PARA EDUCAÇÃO AMBIENTAL
}

\author{
Bernardo Cavalcanti de Almeida ${ }^{1}$ \\ Liliane Jucá Lemos da Silva Porto² \\ Cleyton Martins da Silva ${ }^{3}$
}

\begin{abstract}
Resumo: As Mudanças Climáticas se tornaram um dos assuntos mais discutidos em escala global, revelando a Educação Ambiental como proposta mitigadora para tais questões e, consequentemente, tornando-se uma necessidade para os mais variados níveis de ensino. Neste sentido, o presente artigo discute acerca da elaboração de Histórias em Quadrinhos (HQs), por meio da plataforma PIXTON, como material didático alternativo a ser utilizado na prática da Educação Ambiental em turmas do Terceiro e Quarto Ciclos do Ensino Fundamental ( $5^{a}$ a $8^{a}$ série), na expectativa de fomentar a discussão sobre Mudanças Climáticas, proporcionando o desenvolvimento de cidadãos conscientes e ativos para com as questões ambientais do mundo moderno.
\end{abstract}

Palavras-chave: Educação Ambiental; Histórias em Quadrinhos; Mudanças Climáticas; Aquecimento Global; Efeito Estufa.

Abstract: Climate Change has become one of the most discussed topics on a global scale, revealing Environmental Education as a mitigating proposal for such issues and, consequently, becoming a need for the most varied levels of education. In this context, this article discusses the elaboration of Comics, through the PIXTON platform, as an alternative teaching material to be used in the practice of Environmental Education in elementary school classes, in order to foster the Climate Change discussion and develop conscious and active citizens towards the environmental issues in the modern world.

Keywords: Environmental Education; Comics; Climate Change; Global Warming; Greenhouse Effect.

\footnotetext{
1 Universidade Veiga de Almeida. E-mail: bernardocaval@gmail.com, Link para o Lattes: http://lattes.cnpq.br/4124051480018662 ${ }^{2}$ CRN Engenharia. E-mail: lilianejlp@gmail.com, Link para o Lattes: http://lattes.cnpq.br/7321246800578328

${ }^{3}$ Universidade Veiga de Almeida. E-mail: martins.cleyton@gmail.com, Link para o Lattes: http://lattes.cnpq.br/2637457192603373
} 


\section{Introdução}

A intensa urbanização, associada ao acréscimo no uso dos recursos, geração de resíduos, poluição da água e deterioração da qualidade do ar (SILVA; ARBILLA, 2019, p. 1899), tem se constituído nas grandes questões de preocupações ambientais do mundo moderno.

Outrossim, as atividades antrópicas, sobretudo aquelas referentes ao uso da energia, à agropecuária, aos processos industriais, à destinação de resíduos e ao desmatamento (MOREIRA JÚNIOR et al., 2017, p. 2034) têm contribuído para o aumento na concentração de gases de efeito estufa (GEE) e gerado o consequente aquecimento do planeta.

Segundo o Intergovernmental Panel on Climate Change (IPCC) as elevadas concentrações de GEE e o aquecimento global seriam responsáveis pelas mudanças no clima do planeta e pela intensificação de diversos fenômenos, tais como acidificação dos oceanos, derretimento das calotas polares, elevação dos níveis dos oceanos e perda da biodiversidade (IPCC, 2007; ARTAXO, 2014, p. 9-10).

Neste contexto, Jacobi et al. (2011, p. 137) descrevem que um dos desafios acerca do entendimento das mudanças climáticas e a busca de soluções para as suas consequências se dá na necessidade de mudanças culturais e na correlação entre as ações do cotidiano e as emissões de GEE que levam ao aumento da temperatura da Terra.

Assim, estudos apontam a Educação Ambiental como um instrumento de conscientização individual e coletiva sobre as principais questões ambientais, tendo como consequência a construção de valores e mudanças de comportamento da sociedade, em todos os níveis, de modo a assegurar a participação integral desta na gestão ambiental (ALVES; GUTJAHR; PONTES, 2019, p.70; SILVA, 2019, p.391).

Um aspecto de grande importância para todos os processos educativos é a escolha de materiais didáticos que apresentem linguagem adequada para a sensibilização dos educandos, auxiliando no processo de ensinoaprendizagem, na materialização dos conteúdos e no alcance dos objetivos propostos, devendo estes materiais estarem comprometidos com as atuais demandas sociais (BANDEIRA, 2009, p.15; VILAÇA, 2009, p.7; KAMEL; ROCQUE, 2006).

Outro fator de grande relevância na busca e seleção de um material didático é a necessidade de que este desperte a curiosidade do aluno por meio da valorização de suas experiências extraescolares, e que ao mesmo tempo o aluno seja capaz de participar ativamente na construção do próprio conhecimento. Desta forma, o material didático deve ser lúdico, entusiasmante, passível de releituras e estimulador de novas criações (CARUSO; CARVALHO; SILVEIRA, 2002, p. 5). Destaca-se, neste âmbito, o uso de histórias em quadrinhos como recurso didático, uma vez que a associação de ilustrações ao 
texto constitui uma técnica notável do aumento do interesse e da compreensão por parte do aluno (KAWAMOTO; CAMPOS, 2014, p.150).

Assim sendo, o objetivo deste trabalho é propor a elaboração de uma história em quadrinhos como material didático, mediante o uso de ferramentas da plataforma Pixton para o tratamento das mudanças climáticas, permitindo, assim, a condução de uma estratégia para a implementação da Educação Ambiental (EA).

\section{A Educação Ambiental no Brasil}

Desde que o ser humano passou a ter consciência dos riscos associados à não preservação do meio ambiente, conceitos e abordagens educativas acerca da questão ambiental começaram a ser vislumbradas de forma fragmentada. No entanto, foi somente em 1997, quando se finalizou a construção do Tratado de Educação Ambiental para as Sociedades Sustentáveis e Responsabilidade Global, iniciado em 1992 durante a Conferência das Nações Unidas sobre o Meio Ambiente e o Desenvolvimento (também conhecida como Rio 92), que a EA ganhou destaque no cenário mundial, atraindo cada vez mais o interesse de educadores e ambientalistas (CZAPSKI, 2008, p.15).

Sob o mesmo ponto de vista, em um contexto nacional, a EA teve o seu processo de desenvolvimento iniciado com a criação da Política Nacional de Meio Ambiente (PNMA), em 1981, através da Lei no 6938/81, que dita sobre a necessidade de inclusão da educação ambiental em todos os níveis de ensino, sendo "um componente essencial e permanente da educação nacional, devendo estar presente, de forma articulada, em todos os níveis e modalidades do processo educativo, em caráter formal e não-formal" (BRASIL, 1981).

Ademais ao disposto na PNMA, a EA é assegurada à nação por meio da Constituição Federal (1988), em especial o inciso VI do $\S 1^{\circ}$ do Art. 225, que determina que o Poder Público promova "a educação ambiental em todos os níveis de ensino e a conscientização pública para a preservação do meio ambiente" (BRASIL, 1988).

Contudo, foi somente na década de 1990 que a EA ganhou destaque, uma vez que este período foi marcado por uma série de episódios em prol da EA, tais como a criação dos Núcleos de Educação Ambiental e dos Centros de Educação Ambiental pelo Instituto Brasileiro do Meio Ambiente e dos Recursos Naturais Renováveis (IBAMA) e Ministério da Educação (MEC), respectivamente, assim como a criação do Programa Nacional de Educação Ambiental (ProNEA) pelo MEC e Ministério do Meio Ambiente (MMA) e o estabelecimento de Parâmetros Curriculares Nacionais (PCN) pelo MEC, os quais introduziram o meio ambiente como um tema necessário à todas as disciplinas escolares, sendo legitimado pela Lei $n^{\circ}$ 9.795/99 e pela sua Política Nacional de Educação Ambiental (PNEA), garantindo o direito da população à educação ambiental (CARVALHO, 2008, p.15). 
A EA pode ser definida por diferentes formas, mas o seu fundamento sempre será o mesmo, desenvolver na sociedade a capacidade de preservar e conservar o meio ambiente. A Lei no 9.795/99, que dispõe sobre a Educação Ambiental, define a EA como "(...) os processos por meio dos quais o indivíduo e a coletividade constroem valores sociais, conhecimentos, habilidades, atitudes e competências voltadas para a conservação do meio ambiente" (BRASIL, 1999)

Outrossim, a mesma Lei ratifica a EA como um componente curricular, essencial e permanente, da educação nacional, podendo ser desenvolvida em caráter formal (em instituições públicas e privadas de ensino) e não formal (BRASIL, 1999), sendo este último correspondente às ações e práticas educativas voltadas à sensibilização de populações tradicionais, agricultores e a sociedade em geral sobre as questões ambientais e à sua organização e participação na qualidade do meio ambiente.

No mesmo sentido, os Parâmetros Curriculares Nacionais (PCN) versam que a inserção das questões ambientais de modo transversal e contextualizado em sala de aula contribui com a evolução da consciência ambiental do aluno, estreitando as suas relações com o meio ambiente de forma afetiva e racional, ao mesmo tempo em que forma um cidadão consciente e com autonomia para atuar na melhoria da qualidade ambiental (BRASIL, 1998a).

Entretanto, apesar do estabelecimento de legislação e diretrizes que determinam uma política pública de EA em um cenário nacional, uma distância destas à prática concreta nas instituições de ensino é constantemente observada (JACOBI et al., 2011, p. 140), ressaltando-se a necessidade de elaboração de material didático que permita a adaptação da linguagem, aproximação do conteúdo científico junto ao público alvo e sensibilização da população diante das questões ambientais, tais como as mudanças climáticas, permitindo a proposição de alternativas sustentáveis e viáveis para a solução, mitigação e adaptação destas (ALVES; GUTJAHR; PONTES, 2019, p. 82).

\section{Efeito Estufa, Aquecimento Global e Mudanças Climáticas}

A Terra é aquecida pela energia proveniente da luz do Sol. Segundo SILVA (2012, p.26-27), de 100\% da radiação que incide sobre o planeta, $20 \%$ é refletida pelas nuvens, $4 \%$ pela superfície e $6 \%$ se dissipa no ar, enquanto $19 \%$ da radiação é absorvida, sendo $16 \%$ pelos gases na atmosfera e $3 \%$ pelas nuvens. Deste modo, apenas $51 \%$ alcança a superfície terrestre, aquecendo-a. Tal qual demonstrado na Figura 1, que representa um diagrama do balanço energético na Terra.

Uma vez aquecida, a superfície terrestre emite energia em uma região do espectro chamada de infravermelho térmico, sendo assim energia em forma de calor, que pode ser absorvida (cerca de $15 \%$ ) por gases, cujos movimentos rotacionais e/ou vibracionais sejam coincidentes à frequência da radiação de 
infravermelho emitida. Uma vez absorvida pelos ditos gases, essa energia retorna à atmosfera por meio de calor.

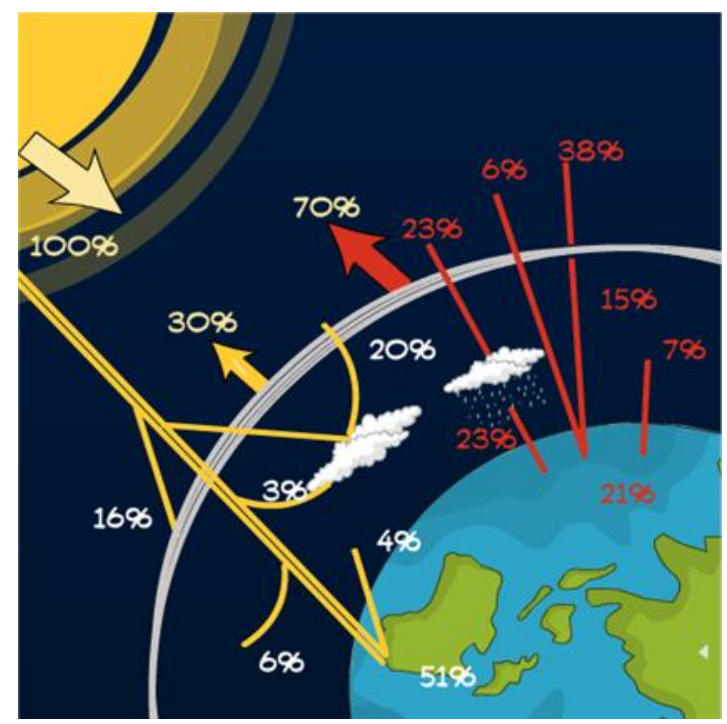

Figura 1: Diagrama esquemático do balanço energético na Terra.

Fonte: Adaptada de Martins, Pereira e Echer (2004).

Assim, o resultado deste balanço energético, em que os ditos gases possuem papel imprescindível, caracterizam o denominado Efeito Estufa, sendo este o responsável pela manutenção da temperatura média da Terra (cerca de $+15^{\circ} \mathrm{C}$ ).

O aumento nas concentrações de GEE, que está associado às atividades antrópicas, tais como a queima de combustíveis fósseis, mudanças no uso da terra e uso de fertilizantes (SILVA et al., 2019, p.564-565; SILVA; CORRÊA; ARBILLA, 2016, p.778), resulta em uma maior quantidade de calor absorvido, elevando a temperatura média da superfície terrestre além dos $15^{\circ} \mathrm{C}$, o que pode ser chamado de efeito estufa intensificado, levando a ocorrência do aquecimento global.

O aquecimento global revela uma elevada criticidade sobre as questões ambientais. Estudos sugerem que nos últimos 100 anos a temperatura média da Terra tem sido elevada para além da sua normalidade, tendo como consequência a variação na troca de energia e umidade entre os diferentes meios, sendo estes fatores determinantes para a observação de variações no clima regional e global (IPCC, 2007; ARTAXO, 2014; OLIVEIRA; ALVES, 2011; RAMOS et al., 2008, p.163).

Ainda neste contexto, diversos estudos (MMA, 2008; IPCC, 2007; PINTO et al., 2010; JACOBI et al., 2015) sinalizam fenômenos secundários como consequências das mudanças climáticas, tais como perturbações no ciclo hidrológico do planeta, elevação no nível dos oceanos, redução da disponibilidade de água para o consumo, desequilíbrio ecossistêmico, perda de 
biodiversidade, desertificação, transtornos na agricultura, deslocamento de cultura, impactos à saúde e ao bem-estar, entre outros.

Assim, Silva (2019, p. 388) descreve as mudanças climáticas como um dos grandes problemas ambientais enfrentado pela sociedade na atualidade, indicando a necessidade de tratativa deste tema por meio da EA.

Jacobi et al. (2011, p. 142) ainda sugerem que as mudanças climáticas devem ser abordadas em uma atividade de EA nos âmbitos nacional, estadual e municipal, de modo a permitir a discussão do tema entre a sociedade e o governo, tornando possível a reflexão, o questionamento e a proposição de soluções para os problemas referentes às mudanças do clima.

\section{Histórias em Quadrinhos (HQs) como material didático para Educação Ambiental}

Diversos estudos indicam que o uso de materiais de cunho didático tem o objetivo de permitir que o processo de ensino-aprendizagem seja realizado com uma abordagem mais concreta, contextualizada, sendo mais eficiente em seus propósitos, uma vez que é tido como um elemento de concepção pedagógica que norteia este processo (FISCARELLI, 2007, p.4; SALES, 2005, p. 3-5).

Sales (2005, p.4) destaca que o material didático deve ser capaz de provocar ou garantir a necessária interatividade do processo ensinoaprendizagem através de uma linguagem dialógica que torne a sua leitura e compreensão leve e motivadora.

Assim, o material didático deve ultrapassar a utilização de letras, palavras e frases, de modo a possibilitar a sensibilização e a persuasão, repassando o conhecimento e difundindo o conteúdo (LISBÔA; JUNQUEIRA; DEL PINO, 2008, p. 29) por meio de interatividade, sequenciação de ideias, estabelecimento de relação entre teoria e prática, além da possibilidade da prática de autoavaliação (SALES, 2005, p.4-5).

Rodrigues e Colesanti (2008, p.65) destacam que a prática da Educação Ambiental tem sido fomentada nos últimos anos tanto por instituições públicas quanto por privadas, tendo como expectativa a formação de cidadãos sensíveis às realidades ambientais e a compreensão da responsabilidade da sociedade sobre 0 meio ambiente, que seriam propulsados por meio de conteúdo visual que, quando presente em um dado material didático, pode auxiliar na intervenção docente no sentido da construção de uma Educação Ambiental.

Deste modo, a elaboração de material didático audiovisual ou impresso para a Educação Ambiental permite uma construção de conhecimentos participativa e emancipatória (RODRIGUES; COLESANTI, 2008, p.65), destacando-se, neste contexto, as Histórias em Quadrinhos (HQs), que

apresentam textos acompanhados de ilustrações, permitindo que os alunos 
correlacionem de maneira mais eficaz os assuntos e histórias que estão sendo retratadas no seu cotidiano (SILVA FILHO; ARAÚJO; SANTOS, 2018, p.1; SALES, 2005, p.5).

Lisbôa, Junqueira e Del Pino (2008, p.37) também destacam que a utilização de HQs no exercício da EA não se apresenta apenas como material de cunho informativo, mas também permite uma maior interação com os seus leitores, possibilitando novas modalidades de assimilação de conteúdo, reflexão e mudanças de comportamento.

\section{Construção de Histórias em Quadrinhos (HQs) por meio de ferramentas da Web 2.0}

As HQs são consideradas um veículo muito importante na transmissão de conhecimentos e sensibilização de leitores, visto que permite uma leitura de fácil compreensão por meio de suas cores, ilustrações e desenhos, possibilitando a sua utilização em problemas complexos, tal como aqueles relacionados às questões ambientais (LISBÔA; JUNQUEIRA; DEL PINO, 2008, p.33) e, deste modo, podem ser vistas como uma nova estratégia educacional em práticas didáticas do cotidiano.

A utilização de HQs para a transmissão de informação já é realizada por jornais há mais de um século, no entanto, até então a sua construção exigia habilidade de seus criadores, e os recursos para a edição de imagens eram limitados. Com o advento da Web 2.0, a construção e utilização de HQs tiveram as suas perspectivas ampliadas com o desenvolvimento de suportes que permitam uma maior democracia no processo de construção de HQs (NICOLAU; MAGALHÃES, 2010, p.2).

O potencial pedagógico das ferramentas da Web 2.0, discutido por Carvalho (2014), contribui para a aprendizagem das temáticas de Ciências Naturais, permitindo o desenvolvimento de novas competências digitais, mediante a criatividade e autonomia.

Neste cenário, muitos sites têm desenvolvido softwares que permitem a seus usuários criar as suas próprias HQs de maneira simples, rápida e objetiva, tais como o StripGenerator, ToonLet, ToonDoo, StripCreator e o PixTon (NICOLAU; MAGALHÃES, 2010, p.10).

Dentre os citados, destaca-se o PixTon ou PixTon Comic, que se trata de um aplicativo da Web 2.0, tendo o software sido criado por Clive e Daina Goodinson, com sede em Parksville, British Columbia, Canadá, e com suporte em português, que permite a criação de HQs com bandas desenhadas e digitais, de forma rápida e gratuita, através de ferramentas como, por exemplo, arrastar e soltar (ANTUNES; GIL, 2016, p. 1517; NICOLAU; MAGALHÃES, 2010, p.11).

O PixTon está disponível de forma gratuita através do endereço: http://www.pixton.com/br/ e se baseia em um sistema de drag-and-drop 
totalmente online, que dispõe personagens, cenários, adereços e balões de fala dentro de um conjunto de painéis, não requisitando que os usuários da plataforma possuam habilidades consideráveis na área da arte ou do desenho (CARVALHO, 2014, p.89).

Cabe ressaltar que apesar de seu uso e acesso serem gratuitos, a plataforma digital PixTon oferece aos seus usuários uma versão não gratuita que permite um maior número de recursos, tais como personagens, emoções faciais, cenários e adereços, que permitem um maior número de possibilidades na criação da $H Q$.

Assim, o PixTon, que funciona em todos os navegadores e plataformas modernas MAC, Windows, Chromebooks, Linux, iOS e Android, pode ser utilizado como ferramenta de fácil acesso para a construção de material didático e pedagógico, uma vez que os recursos para a utilização desta são consideradas de fácil aquisição.

Deste modo, para este trabalho, utilizou-se o PixTon para a elaboração de um material didático a ser utilizado como ferramenta para uma abordagem mais contextualizada na Educação Ambiental, sobretudo no que diz respeito ao Aquecimento Global e às Mudanças Climáticas.

\section{Abordagem e Contextualização das Mudanças Climáticas por meio de HQs}

A elaboração e construção de HQs para abordagem e contextualização do tema Mudanças Climáticas foram planejadas tendo em vista os Parâmetros Curriculares Nacionais para o Terceiro e Quarto Ciclos do Ensino Fundamental (5 a $8^{\text {a }}$ série) no tangente a aplicação nas áreas de Ciências Naturais, Geografia e Meio Ambiente (BRASIL, 1998a; BRASIL, 1998b; BRASIL, 1998c), onde a abordagem do tema pode contribuir para um posicionamento mais crítico do aluno (BRASIL, 1998a, p.221)

O primeiro passo para o desenvolvimento deste trabalho foi a elaboração de uma história, com a criação de um enredo, para que este pudesse ser ilustrado e narrado por meio de uma HQ.

Deste modo, posteriormente, o PixTon foi acessado e utilizado, por meio do endereço http://www.pixton.com/br/, e através de uma conta gratuita, a qual, apesar de apresentar limitações quanto aos recursos disponíveis, permitiu a construção de uma $\mathrm{HQ}$ sobre Mudanças Climáticas.

Assim, a ideia desenvolvida conta a história de uma criança que, após assistir uma aula sobre Efeito Estufa e Mudanças Climáticas, vislumbrou e enfrentou em seus sonhos mais profundos diversas situações decorrentes das consequências das Mudanças Climáticas, tais como variações extremas de temperatura, desertificação, escassez de água e intensificação de fenômenos atmosféricos. 
A história tem o seu término com o despertar da criança, em um momentâneo de alívio por ter percebido ser um pesadelo, porém diante da frustração e tristeza ao entender que muitas dessas consequências já estão a acontecer na realidade.

Sob um olhar mais crítico, a construção da HQ pode ser dividida e observada em quatro blocos distintos, cada qual representando uma figura com uma sequenciação de quadrinhos, como pode ser vista na Figura 2, Figura 3, Figura 4 (subdividida em Figura 4a e Figura 4b) e Figura 5.

A visualização da $\mathrm{HQ}$ na íntegra e com melhor resolução pode ser feita através da plataforma Pixton no link https://pixton.com/hq:jslcxxbi.
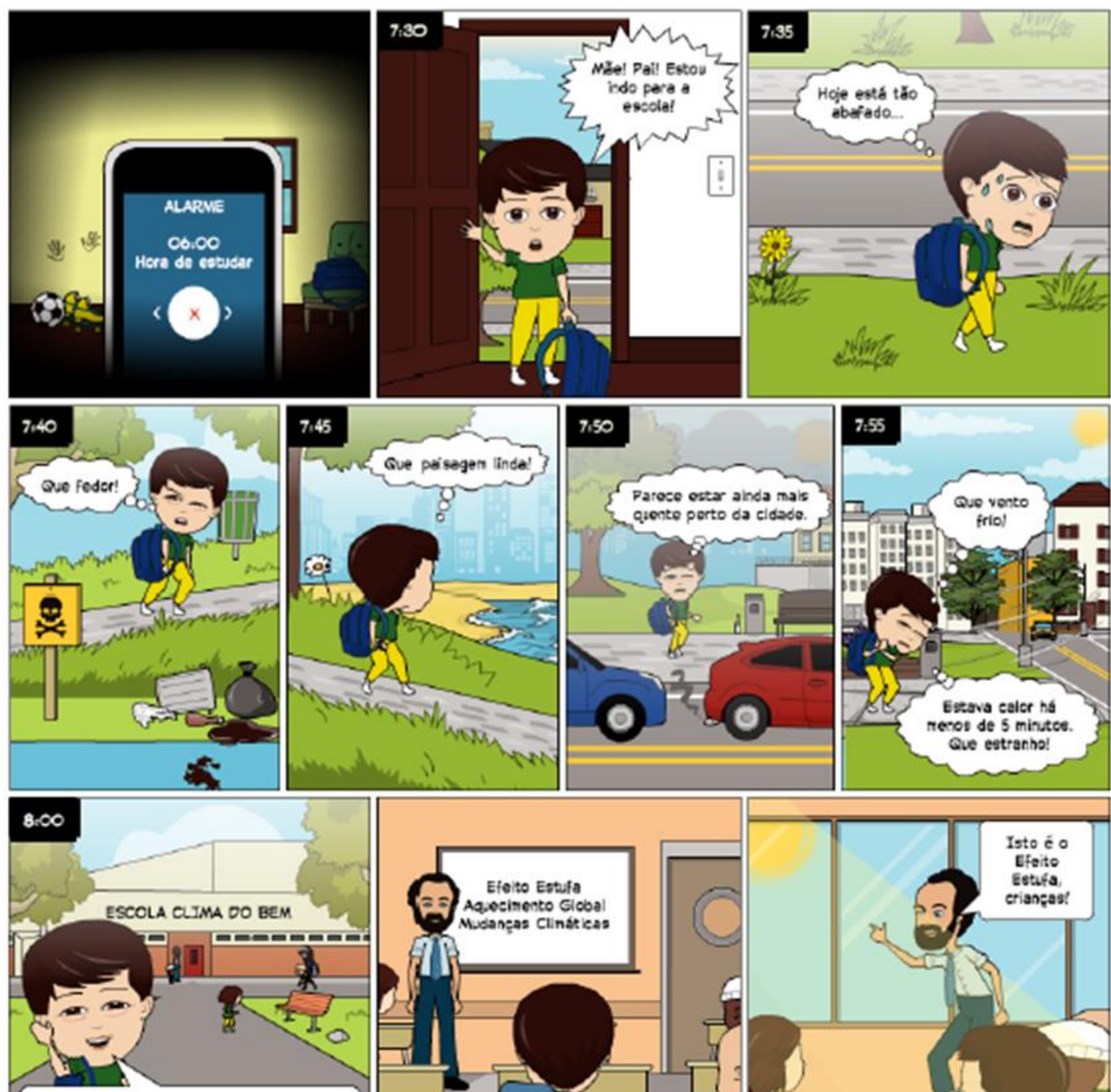

Hejo eu veu aprendor sobre Eloito Estifa. Aqiocimento Gicba a Nudanças Cimsticas. Vanos aprender jurtos?

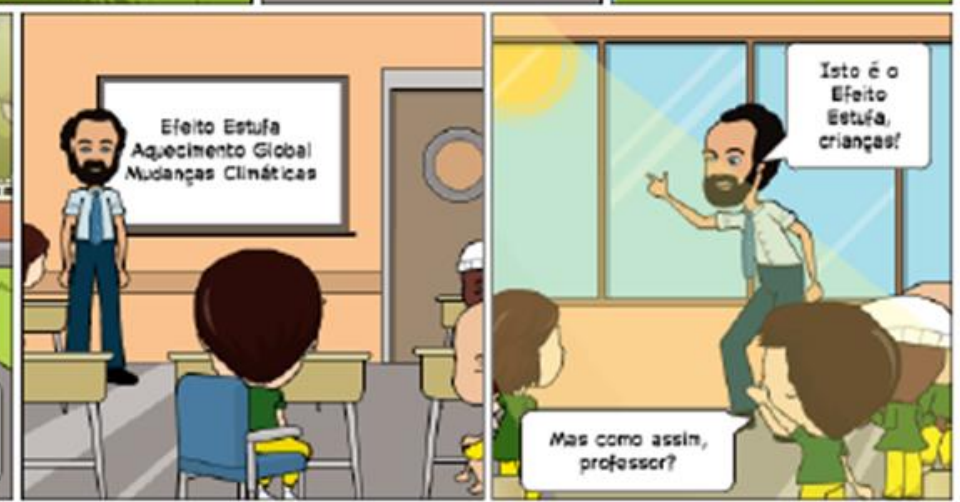

Figura 2: A inserção do leitor no contexto da HQ.

Fonte: Almeida, 2018. 
No primeiro bloco de quadrinhos, expresso pela Figura 2, a história se assemelha a realidade tal como ela é, de modo a fazer com que o leitor seja capaz de se enxergar no lugar do personagem e de interligar os fatos que se seguem com a sua realidade.

Neste sentido, para que o educando se conecte à história, ele precisa se sentir representado e desenvolver uma espécie de vínculo com o contexto retratado nos quadrinhos, o que lhe permite entender melhor a narrativa da história, possibilitando um avanço na construção de sua identidade (ALBA, G.; BARRETO; ALBA, P., 2015; SILVA FILHO; ARAÚJO; SANTOS, 2018).
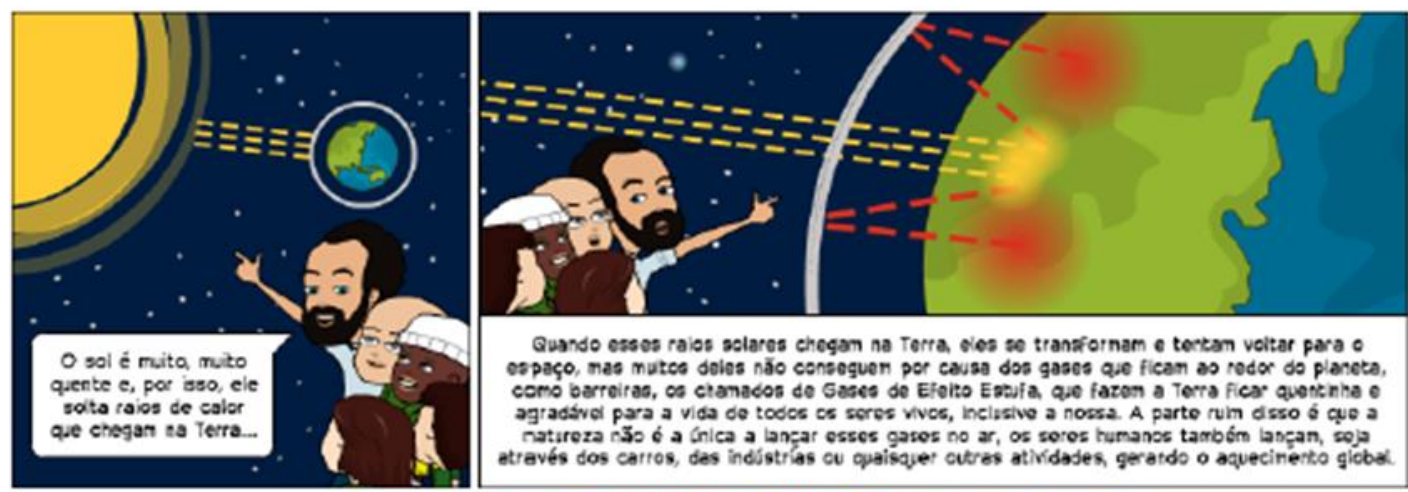

Quando essos raios selares chegan na Terra, wies se transfornam e terten veltar para o ospaço, mas mutce dolos năo consoguen por causa dos gases que ficam as rodor do planeta, como barreiras, os ctanados do Gases de Eloito Eabufa qu fazon a Terra ficar quentrina o agradivel para a vida de todos os scros vives, incissive a nossa. A parto rum disso 6 cue a natireza n3o 6 a unica a lancar osses gases no ar, or sores humanos também lascan, soja

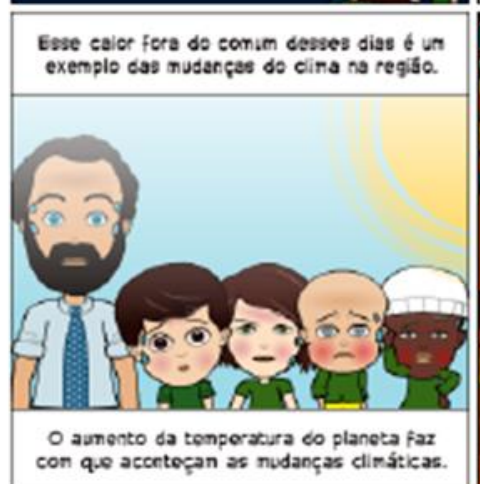
etraves dos calros, das indistrias ou quaisquet cutras atividades, geratdo o aquecinertio globak.
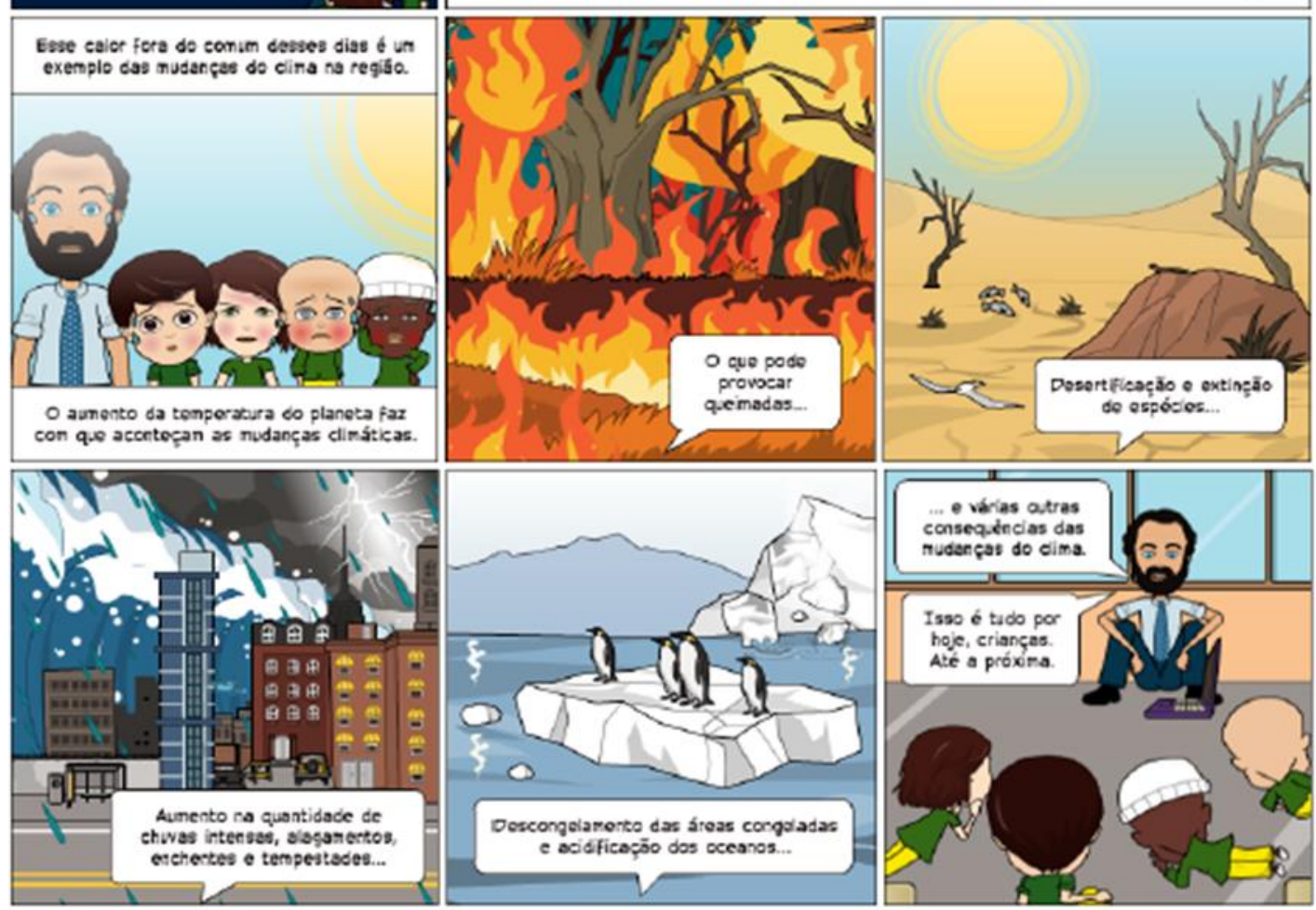

Figura 3: Levantamento dos temas.

Fonte: Almeida, 2018.

\section{Fonte: Almeida, 2018.}

No segundo bloco, na Figura 3, buscou-se tratar dos temas intrínsecos ao entendimento da $\mathrm{HQ}$, tais como Efeito Estufa, Aquecimento Global e 
Mudanças Climáticas, utilizando-se de linguagem simples e ilustrações para facilitar o entendimento do leitor acerca do tema.

Diante da figura de um professor conversacional e de uma aula interativa fazendo uso de um laptop, no qual todas as crianças se mantiveram atentas a explicação e confortáveis com a didática aplicada (conforme demonstrado no sexto e último quadrinhos da Figura 3), o leitor pode associar a ludicidade da aula à aprendizagem dos alunos.

Tal como sugerem Carmo et al. (2017), o educador, ao optar pelo lúdico, principalmente na Educação Infantil, possibilita que a criança se sinta disposta a participar das atividades escolares e a perpassar seus conhecimentos a outrem.

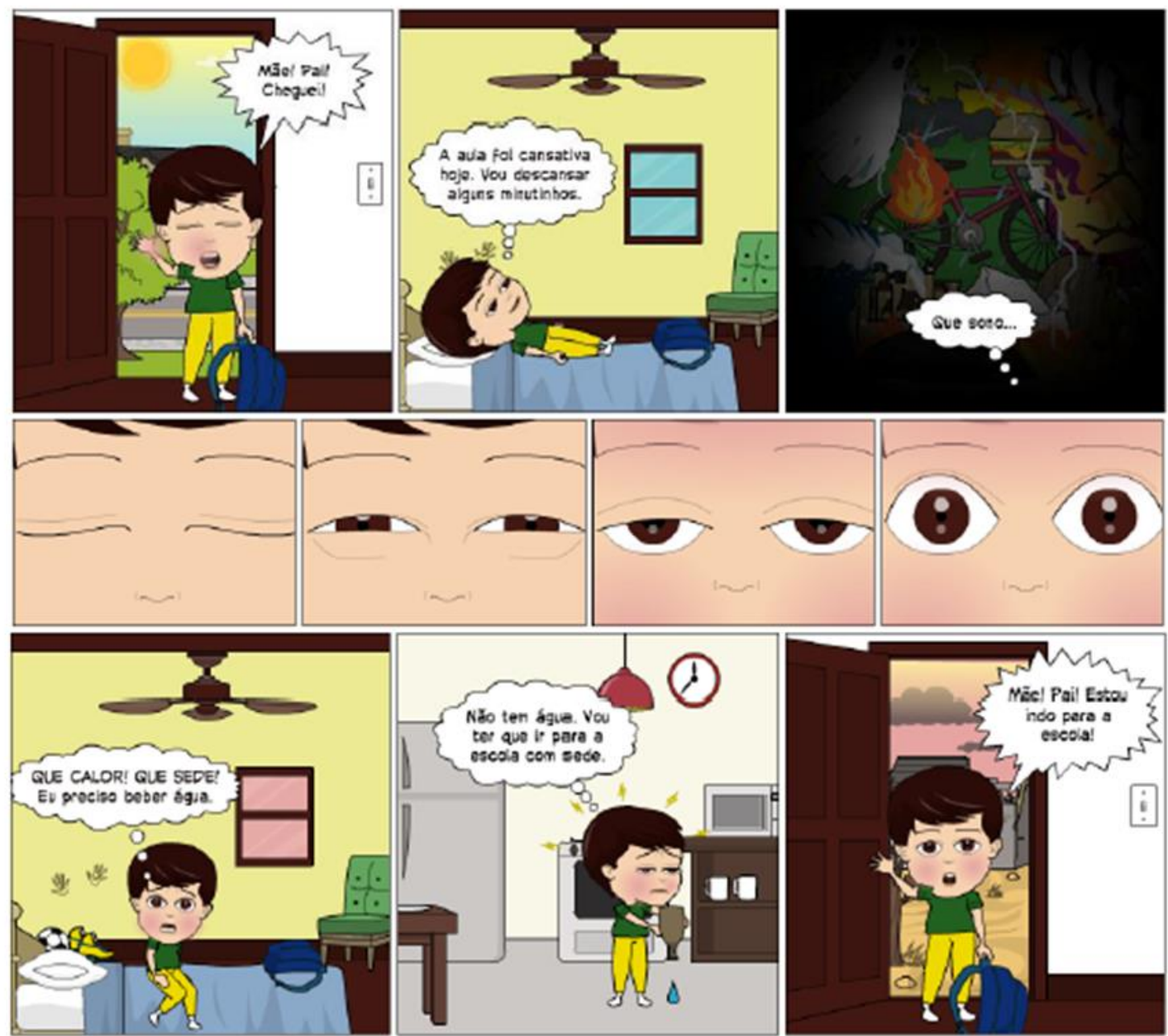

Figura 4a: O primeiro acesso a ludicidade dos temas.

Fonte: Almeida, 2018.

Com o terceiro bloco (Figura 4a e Figura 4b), na Figura 4a há uma transição do real para o imaginário, a qual acontece de forma lúdica e 
minuciosa a fim de que o leitor adentre no imaginário do personagem e perceba os pormenores dos temas discutidos.

No momento após a transição, o qual ocorre imediatamente após a abertura dos olhos do personagem, o entendimento da história é passível de seguir por um caminho diferente do proposto, isto é, em vez do leitor compreender que o personagem está sonhando, ele pode deduzir que o personagem tenha de fato despertado, o que em nada impede o transcorrer da história.

Desta forma, já dentro do imaginário do personagem, as consequências das Mudanças Climáticas surgem paulatinamente dentro de sua rotina, o que pode ser observado em continuidade na Figura 4b.
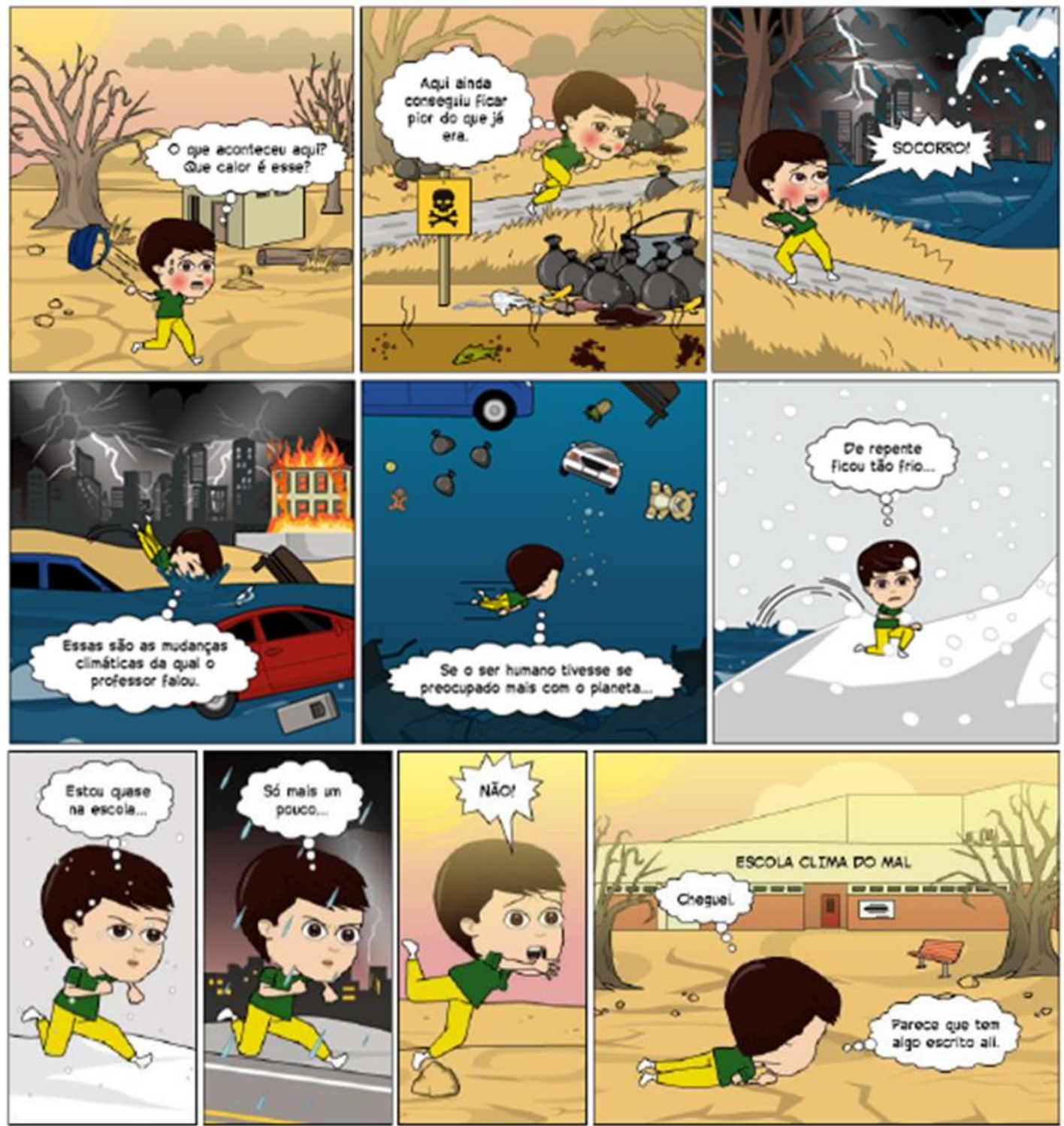

Figura 4b: A ludicidade das consequências das Mudanças Climáticas.

Fonte: Almeida, 2018. 
Em sequência à Figura 4a, a Figura 4b evidencia as consequências das Mudanças Climáticas de forma crítica e surrealista, perpassando por todo o trajeto concernente à rotina do personagem até a escola.

No imaginário do personagem, os quadrinhos começam na Figura 4a com a ausência de água e na Figura $4 b$ apresentam-se outras consequências, como aumento da temperatura, desertificação, tempestades, inundação, frio intenso e instabilidade climática.

A imagem que se pretende passar com o personagem dando continuidade ao seu trajeto, mesmo diante dos mais variados intempéries, trata-se de um aluno com foco e determinação para aprender.

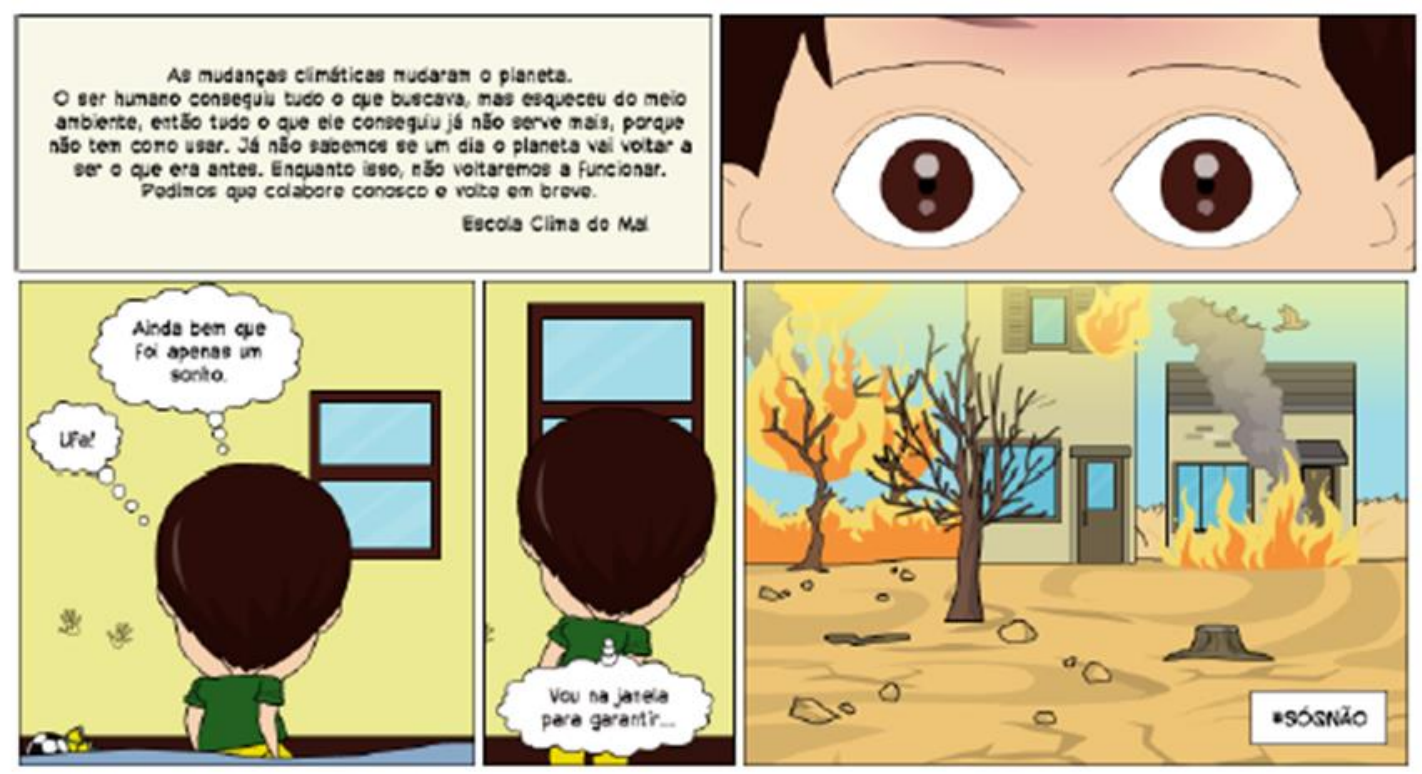

Figura 5: Reflexão acerca das Mudanças Climáticas na realidade.

Fonte: Almeida, 2018.

No último bloco, a Figura 5 remete o leitor a reflexão, uma vez que nos três últimos quadrinhos, o personagem, ao acordar do pesadelo e perceber que os acontecimentos por ele vividos não estavam apenas no seu imaginário, permite que o leitor assimile as consequências das Mudanças Climáticas e faça as devidas comparações com a realidade.

Além disso, tal constatação possibilita ao leitor a percepção de que as ações antrópicas são responsáveis pelas Mudanças Climáticas e, embora as consequências das Mudanças Climáticas não estejam na mesma escala do apresentado na $\mathrm{HQ}$, viabiliza a associação dos acontecimentos da $\mathrm{HQ}$ com os acontecimentos da realidade. 


\section{Considerações finais}

As questões ambientais têm estado cada vez mais presentes na vida das pessoas, quer seja nos meios de comunicação, quer seja como pauta em discussões e debates tanto nacionais quanto internacionais.

As Mudanças Climáticas e os temas a ela atrelados, tais como Efeito Estufa e Aquecimento Global, configuram-se como os assuntos ambientais mais recorrentes dos tempos atuais, haja vista a necessidade de controle das atividades antrópicas sobre o meio ambiente, uma vez que os impactos gerados pelo homem se tornaram maiores e mais contundentes nos últimos anos, demandando ações contrárias ao consumismo desenfreado e, neste sentido, à proteção e manutenção da integridade ambiental.

A Educação Ambiental, neste contexto, passa a ter papel fundamental na tratativa de tais problemas, tendo sido integrante dos Parâmetros Curriculares Nacionais desde a década de 1990 em um cenário nacional.

Desta forma, tendo em vista a relevância da Educação Ambiental no ambiente escolar, o presente artigo contribui com a discussão e prática desta, bem como auxilia na construção de recursos didáticos alternativos lúdicos e de linguagem simples, tais como a elaboração de Histórias em Quadrinhos por meio de ferramentas da Web 2.0, a plataforma Pixton, com o intuito de abordagem do tema das Mudanças Climáticas em turmas do Terceiro e Quarto Ciclos do Ensino Fundamental (5 $5^{\underline{a}}$ a 8aㅡ série).

Diante da importância da utilização de um material didático nas salas de aula, a História em Quadrinhos retratada neste artigo serve a seu propósito, e fomenta o desenvolvimento de trabalhos futuros acerca da temática.

\section{Referências}

ALBA, G. O.; BARRETO, F. O.; ALBA, P. F. S. Um olhar sobre Educação Ambiental e Sustentabilidade. In: Congresso Nacional de Educação EDUCERE, XII, 2015, Curitiba. Anais... Curitiba: PUCPR, 2015. Disponível em: <https://educere.pucpr.br/p1/anais.html>. Acesso em: 28 julho 2019.

ALVES, R. J. M.; GUTJAHR, A. L. N.; PONTES, A. N. Processo metodológico de elaboração de uma cartilha educativa socioambiental e suas possíveis aplicações na sociedade. Revista Brasileira de Educação Ambiental, v. 14, n. 2, p. 69-85, 2019.

ANTUNES, A; GIL, H. Ensinar e aprender através da banda desenhada digital Pixton: no 10 CEB. In: Atas XIII Congresso SPCE. Escola Superior de Educação de Viseu, 2016. p. 1515-1523.

ARTAXO, P. Mudanças climáticas e o Brasil. Revista USP, n. 103, p. 8-12, 2014. 
BANDEIRA, D. Material didático: conceito, classificação geral e aspectos da elaboração. Curso de Materiais didáticos para smartphone e tablet. Curitiba, IESDE, p. 13-33, 2009.

BRASIL. Secretaria de Educação Fundamental. Parâmetros curriculares nacionais: meio ambiente. Brasília, DF: MEC/SEF, 1998a. Disponível em: $<$ http://portal.mec.gov.br/seb/arquivos/pdf/meioambiente.pdf>. Acesso em: 14 julho 2019.

BRASIL. Secretaria de Educação Fundamental. Parâmetros curriculares nacionais: ciências naturais. Brasília, DF: MEC/SEF, 1998b. Disponível em: $<$ http://portal.mec.gov.br/seb/arquivos/pdf/ciencias.pdf>. Acesso em: 14 julho 2019.

BRASIL. Secretaria de Educação Fundamental. Parâmetros curriculares nacionais: geografia. Brasília, DF: MEC/SEF, 1998c. Disponível em: $<$ http://portal.mec.gov.br/seb/arquivos/pdf/geografia.pdf>. Acesso em: 14 julho 2019.

BRASIL. Lei no 6.938, de 31 de agosto de 1981. Institui a Política Nacional do Meio Ambiente e dá outras providências. Brasília. Disponível em: $<$ http://www.planalto.gov.br/ccivil 03/Leis/L6938.htm>. Acesso em: 17 julho 2019.

BRASIL. Lei no 9.795, de 27 de abril de 1999. Dispõe sobre a educação ambiental, institui a Política Nacional da Educação Ambiental e dá outras providências. Brasília, Disponível em: $<$ http://www.planalto.gov.br/ccivil 03/LEIS/L9795.htm>. Acesso em: 14 julho 2019.

BRASIL. Constituição da república federativa do Brasil. Brasília: Senado Federal, Centro Gráfico, 1988. Disponível em: <http://www.planalto.gov.br/ccivil 03/constituicao/constituicaocompilado.htm.> Acesso em: 14 julho 2019.

CARUSO, F.; CARVALHO, M.; SILVEIRA, M. C. Uma proposta de ensino e divulgação de ciências através dos quadrinhos. Ciência \& Sociedade, v. 8, p. 5, 2002.

CARVALHO, I. C. M. A educação ambiental no Brasil. In: BRASIL. Salto para o Futuro: Educação Ambiental no Brasil. Brasília: v. 18, Boletim 1, 2008.

CARVALHO, S. M. I. E. O potencial pedagógico das ferramentas da Web 2.0 no ensino online das Ciências Naturais: a perspectiva dos alunos. Tese de Doutorado. Universidade de Lisboa. 2014.

CZAPSKI, S. Os diferentes matizes da Educação Ambiental no Brasil: 1997-2007. Ministério do Meio Ambiente, Secretaria de Articulação Institucional e Cidadania Ambiental. Departamento de Educação Ambiental, 2009.

FISCARELLI, R. B. O. Material didático e prática docente. Revista IberoAmericana de estudos em educação, v. 2, n. 1, p. 31-39, 2007. 
IPCC. Intergovernmental Panel on Climate Change. IPCC 2007. Climate Change 2007: The Physical Science Basis. Contribution of Working Group I to the Fourth Assessment Report of the Intergovernmental Panel on Climate Change. Cambridge University Press, Cambridge, United Kingdom and New York, NY, USA, 2007. Disponível em: <https://www.ipcc.ch/report/ar4/wg1/>. Acesso em: 16 julho 2019.

JACOBI, P. R. et al. Mudanças climáticas globais: a resposta da educação. Revista Brasileira de Educação, v. 16, n. 46, p. 135-148, 2011.

JACOBI, P. R. et al. Temas atuais em mudanças climáticas: para os ensinos fundamental e médio. São Paulo: IEE - USP, 2015

KAMEL, C.; ROCQUE, L. de. As histórias em quadrinhos como linguagem fomentadora de reflexões - uma análise de coleções de livros didáticos de ciências naturais do ensino fundamental. Revista Brasileira de Pesquisa em Educação em Ciências, v. 6, n. 3, 2006.

KAWAMOTO, E. M.; CAMPOS, L. M. L. Histórias em quadrinhos como recurso didático para o ensino do corpo humano em anos iniciais do Ensino Fundamental. Ciência \& Educação, p. 147-158, 2014.

LISBÔA, L. L.; JUNQUEIRA, H.; DEL PINO, J. C. Histórias em quadrinhos como material didático alternativo para o trabalho de Educação Ambiental. Gaia scientia, João Pessoa, v. 2, n. 1, p. 29-39, mar. 2008.

MMA. MINISTÉRIO DO MEIO AMBIENTE. Mudanças climáticas. In: Conferência Nacional do Meio Ambiente, 3, 2008, Brasília. Anais... Brasília, 2008.

MOREIRA JÚNIOR, D. P. et al. Determinação de gases do efeito estufa em cinco capitais de diferentes biomas brasileiros. Revista Virtual de Química, v. 9, n. 5, 2017.

NICOLAU, V.; MAGALHÃES, H. Arte sequencial ao alcance de todos: as novas possibilidades de criação e veiculação de tirinhas nas mídias digitais. In: Congresso de Ciências da Comunicação na Região Nordeste, XII, Campina Grande. Anais... Campina Grande: Intercom, 2010. Disponível em: $<$ http://www.intercom.org.br/papers/regionais/nordeste2010/trabalhos.htm>.

Acesso em: 29 julho 2019.

OLIVEIRA, R. D. F.; ALVES, J. W. S. Mudanças climáticas globais no Estado de São Paulo. Governo do Estado de São Paulo, Secretaria do Meio Ambiente, 2014.

PINTO, E. P. P. et al. Perguntas e respostas sobre aquecimento global. Instituto de Pesquisa Ambiental da Amazônia, 2010.

RAMOS, M. A. B. et al. Mudanças climáticas. Geodiversidade do Brasil, p. $163,2008$. 
RODRIGUES, G. S. S. C.; COLESANTI, M. T. M. Educação ambiental e as novas tecnologias de informação e comunicação. Revista Sociedade \& Natureza, v. 20, n. 1, 2008.

SALES, M. V. S. Uma reflexão sobre a produção do material didático para EaD. Anais do XII Congresso Internacional de Educação a Distância, ABED. 2005.

SILVA, C. M. Avaliação de gases efeito estufa na cidade do Rio de Janeiro. Dissertação de Mestrado. Universidade do Estado do Rio de Janeiro, 2012.

SILVA, C. M.; ARBILLA, G. Urbanização e os desafios na caracterização da qualidade do ar. Revista Virtual de Química, v. 10, n. 6, 2019.

SILVA, C. M.; CORRÊA, S. M.; ARBILLA, G. Determination of $\mathrm{CO} 2, \mathrm{CH} 4$ and N2O: a Case Study for the City of Rio de Janeiro Using a New Sampling Method. Journal of the Brazilian Chemical Society, v. 27, n. 4, p. 778-786, 2016.

SILVA, C. M. et al. Main Greenhouse Gases levels in the largest secondary urban forest in the world. Atmospheric Pollution Research, v. 10, n. 2, p. 564570, 2019.

SILVA, E. M. O papel da Educação Ambiental nas ações de combate as mudanças climáticas. Revista Brasileira de Educação Ambiental, v. 14, n. 2, p. 387-396, 2019.

SILVA FILHO, S. S.; ARAÚJO, E. F.; SANTOS, G. A. A construção de histórias em quadrinhos utilizando a ferramenta Pixton: uma alternativa para o ensino de química. Ciclo Revista, v. 3, n. 1, 2018.

VILAÇA, M. L. C. O material didático no ensino de língua estrangeira: definições, modalidades papéis. Revista Eletrônica do Instituto de Humanidades, v. 8, n. 30, p. 1-14, 2009. 